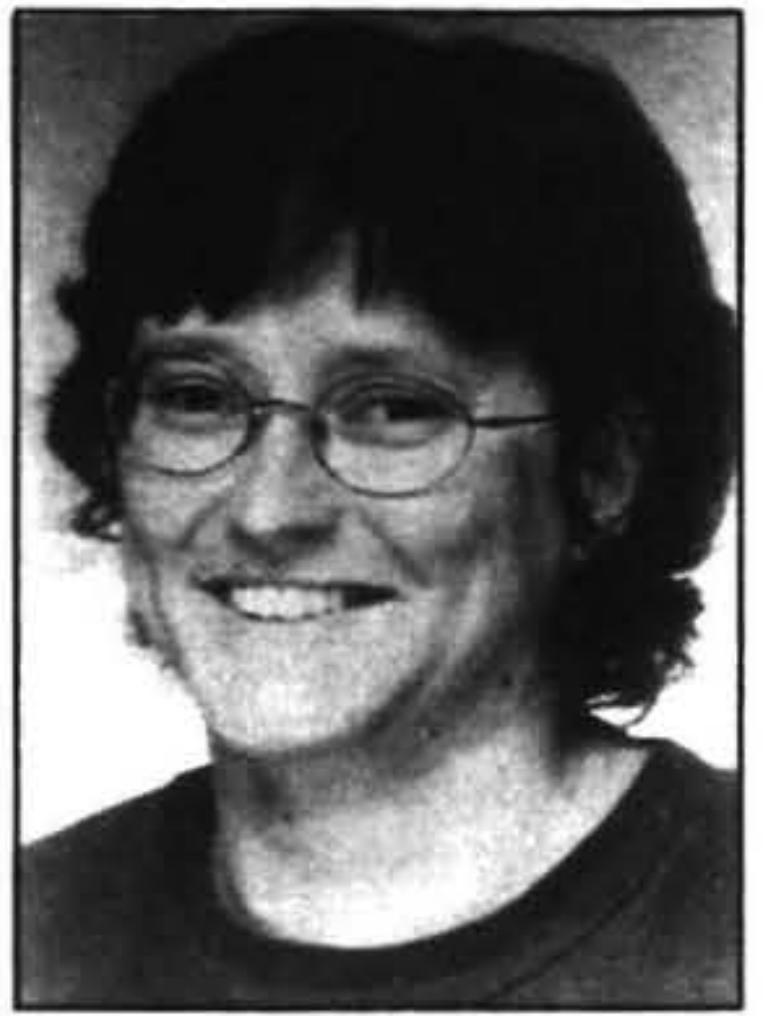

\title{
STUDYING WORK IN THE POST REFORM ERA
}

\author{
Cushla Paice, Carl Davidson, \\ Hilary Bennett, Mike O'Brien
}

\author{
Departments of Economics, Sociology, \\ Psychology, Social Policy and Social Work \\ Massey University, Albany Campus, Auckland
}

\begin{abstract}
This paper emerged from the first stage of what is to be a three-stage multi-disciplinary research project examining work in the 'post-reform era'. The key foci of that research project are the organisation of work, the determination of wages, and the well-being of workers at the workplace level. It will examine how the nature of work varies across workplaces of different sizes and in different competitive environments. The present paper draws on the first stage of the research to share some of the problems experienced while attempting to study workplaces in New Zealand today. It draws on research in 19 Auckland workplaces and reveals serious definitional, theoretical, and methodological problems that are likely to constrain any such research in the present environment. In our case, the problems raised, and the solutions offered, have led to a fundamental rethink of the larger project's research objectives, strategies, and ways to operationalise concepts into empirical measures.
\end{abstract}

This paper represents an initial, and very modest, attempt to bring together three threads apparent in research into work in New Zealand. The first thread represents the changing nature of work in New Zealand given changes in the competitive and legislative environment of the last decade; the second represents interest in the role of small business in shaping work and labour market outcomes; the third responds to recent calls for a workplace survey along the lines of the British and Australian industrial relations surveys (see Ryan 1996).

The authors set out to build up a picture of what work is like across businesses of different types by undertaking a workplace survey which includes small business and attains matched information from both managers and employees. Such a cross section can be used as the basis for comparative analysis looking at the effect of workplace characteristics on the organisation of work, wages and conditions and employee well-being. We foresaw some methodological problems regarding measurement of variables and as an initial stage to the research we interviewed managers at 19 workplaces around Auckland and left a structured questionnaire for managers and a separate questionnaire for employees.

While the initial goals of the research (and hence the intent of this paper) was to talk about our substantive findings, as the process of our research unfolded it became obvious that we were learning more about the problematic nature of researching work in New Zealand than we were about working arrangements themselves. Consequently, in this paper we set out the problems we came up against and offer some suggestions for how they might be overcome in future work. Some of the issues we had foreseen but others arose from the research itself. As well as some practical suggestions about how to approach employers in future workplace surveys our work suggests that a more fundamental rethink of research objectives and how to operationalise concepts into empirical measures is required.

\section{Research objectives and methodology}

The research team from varied academic backgrounds (economics, political science, psychology, and sociology), was formed around the shared interest in building a picture of what work is like today. This involved collecting information from a cross-section of workplaces which could then be used for comparative analysis across businesses of different types.

Our approach differs from previous $\mathrm{NZ}$ research in two main ways. First, we aim to include small business in the survey. Small business have either been excluded from previous surveys or have shown a low response rate. The "Labour Market Adjustment Under the Employment Contracts Act Surveys" commissioned by the Department of Labour sample all enterprises with 4 or more full time equivalent employees. The excluded small businesses represented $7 \%$ of employees in 1993 and 5\% in 1996. The Victoria University collective employment contracts database is derived from surveys of employers with 20 or more staff and had a $36 \%$ response rate from employers in the $20-50$ staff range and $67 \%$ response rate from larger employers (Harbridge 1993). Even in overseas surveys small business have been excluded or asked different questions such that a comparison with larger businesses is not possible (e.g. AWIRS has a 
separate phone survey of workplaces with fewer than 20 employees).

We think it is important to include the small business sector and ask questions that can be used for comparisons between small and large workplaces. Enterprises with fewer than 6 full time equivalent employees have a $23 \%$ share of employment according to Department of Statistics Business Activity Statistics for February 1995. This share is higher again for activity units with fewer than 6 employees, at $25.5 \%$ of total employment. There is some overseas evidence that this share of employment is increasing although because of data limitations they may be measuring the share of new jobs rather than net changes and the evidence is not convincing yet. Department of Statistics notes that between 1987 and 1994 there was growth in the number of establishments with fewer than 20 employees (from $94 \%$ to $95.4 \%$ ) and growth in their share of full time equivalent employees (from $42.4 \%$ to $49 \%$ ). Also the small business sector has been changing in composition with changes in the number of small self employed operators who may have previously been employees (Bradford, 1993; Haines, 1991). This in turn is changing the competitive environment that companies are operating in.

Firms in the small business sector have been characterised in the literature as lacking explicit employment contracts or structured career paths and as having more flexible work practices and customised products compared to their large firm counterparts (see Hamilton and English, 1993). It is perhaps these aspects that have lead people to speculate that this sector will show the greatest effects of change in the regulatory and legislative environment such as the Employment Contracts Act. But this is not necessarily the case. It is possible that this sector with a more personal relationship between managers and employees was least 'restricted' by a centralised awards system or unionisation and as such would change the least with changes in the legislative environments. Where effects are felt the most is an empirical question.

A second distinguishing feature of our approach is an attempt to get matched workplace and employee data. Theoretically, having matched data allows researchers, who are interested in examining the impact of workplace characteristics on wages and conditions, to control for individual characteristics of employees which affect their earnings capacity. Also when examining wage differentials between demographic groups there is a need to control for workplace characteristics such as the competitive environment, feminisation of labour, capital intensity and union presence. Another advantage of having matched data is that it enables researchers to consider both management and workers perceptions of the same workplace environment.

The purpose of this initial stage of the research was to get some feedback on how our method of approaching workplaces and how our questions would work.

This was based on 19 workplaces from around the Auckland area. These were selected using 'purposive sampling'. This is a sampling method where the research team purposely choose subjects who, in their opinion, are seen to be relevant to the research topic. In this case, the judgement of the research team is more important that trying to achieve a probability based random sample (see Sarantakos, 1993). The key factors that the sample needed to cover were sector of activity (manufacturing or service) and size. With regards to size, it is important to distinguish between size of the workplace with its associated technologies and training requirements and company size with its associated access to resources and management philosophies. Accordingly the goal was to sample workplaces in three size groups: a Small Business sector (small companies), an Extensive sector (small workplaces operated by large companies) and an Intensive sector (large workplaces). We wanted the final sample to include businesses as shown in Table One.

\section{Table 1. Desired Sampling Matrix}

\begin{tabular}{lccc}
\hline & $\begin{array}{l}\text { Small Business } \\
\text { Company }=<25\end{array}$ & $\begin{array}{l}\text { Extensive' } \\
\text { Company }=<25\end{array}$ & $\begin{array}{l}\text { 'Intensive' } \\
\text { Company }=<25\end{array}$ \\
\hline Manufacturing & 4 & 4 & 2 \\
Services & 4 & 4 & 2 \\
\hline
\end{tabular}

Workplaces were identified using the 1996 New Zealand Business Who's Who which was supplemented with the Auckland 1996 Yellow Pages. Fifty seven workplaces in total were sent information about the research and invited to participate. These were followed-up with a phone call until the target numbers for certain business types in the matrix were achieved. The end result was that 19 workplaces took part in the research. We are painfully aware that this sampling method has considerable flaws but reiterate that this was the initial stage of the research designed to generate some preliminary data and to help fine-tune the research method and instruments.

Data were gathered from those 19 workplaces using the 'layered' sources technique familiar in anthropological research. (see Leibrich, 1993). In-depth qualitative interviews with management were supplemented with self-administered questionnaires left for both management and employees.

\section{Lessons from the workplaces}

This exercise provided some important lessons about researching workplaces. Perhaps the most important of these are about the need to reassess research objectives and redefine concepts such as "non-standard". But as well as these issues there are some practical lessons about how to approach workplace managers and their employees to ensure an adequate response rate and relevant matched data.

\section{Definitional issues}

First we were faced with the task of defining 'small' business, an issue plaguing any empirical research involving workplaces. While $90 \%$ of all New Zealand businesses employ less than 10 people (Hamilton and English, 1993:4), 
the number of employees which counts as 'small' varies in the international literature, making comparisons difficult. The cut-off point between small and large is necessarily arbitrary and should vary according to the variable of interest. For example if small business are considered to be different because of the personal nature of interaction between owners and employees then the cut-off point may be smaller than if the variable of interest is capital intensity.

For the purpose of achieving a range in our sample we eventually decided that less than twenty five employees would be our cut-off point. This of course raised the question whether we were talking about 25 employees or 25 full time equivalents. This begs the question whether the unit of analysis here is employees - is it the number of people that a business employs which influences the way it organises its work - or if it is really full time equivalent positions.

But perhaps an even more important issue to raise is how to define concepts describing different types of employment. In particular definitions of 'casual' versus 'permanent' work and 'contract' work. We spent some time fine-tuning definitions which have been used in the literature. We ended up with the definitions set out in Table Two.

\section{Table 2. Definitions}

Employees

all people paid a salary or wages by this employer and who work at or from this workplace including managers and including those employees who are cur rently on paid leave.

Contractors/

Consultants

Fulltime, permanent employees

Part-time, permanent employees

people who provide a finished product or service to the workplace but who have control over how and when to do the work themselves.

those who work at least 30 hours per week and have on-going or regular employment here. (This includes those on rotating shifts who may work different hours each week).

work less than 30 hours per week but have regular employment. (This includes those on rotating shifts who may work different hours each week).

Full time casual work at least 30 hours per week and work employees on call as needed rather than regular hours per week.

Part time casual work less than 30 hours per week and employees work on call as needed rather than regular hours per week.

Definitions of casual employees, used in empirical studies have sometimes been dictated by data limitations to be those employees who are not entitled to paid holiday leave or sick leave or those employees who could be dismissed without notice (National Board of Employment, Education and Training 1992). We decided that the essential difference between casual and permanent work was working on call as needed rather than regular hours per week on an on-going basis.

These definitions were printed at the beginning of management questionnaires and repeated with appropriate questions, for instance, a question about the number of casual employees would include "by 'casual employees' we mean...".However, despite the time spent fine-tuning these definitions and spelling them out in the questionnaire, the research soon revealed that they were problematic.

Casual Work: We found such variation in employers' perceptions of what "casual" and "permanent" meant such that permanent employees in some workplaces were the same as casual employees in others and that in some workplaces casuals were not considered to be part of the workforce. For instance, at one workplace, a small business in the service sector, the three employees were counted as 'permanent' even though they were not entitled to paid annual or sick leave and had hours which varied according to weather patterns. We would define these as permanent employees because the work was on an on-going basis. In contrast, another service organisation with 47 employees, 7 were considered permanent and 40 casual employees. Although these employees were classified as casual, their jobs were on an on-going basis.

At one workplace the manager, referred in the interview to "someone who comes in some weekends but doesn't really work here". We would count this as a casual employee who comes in if required but in the manager's mind they did not work there and they were not counted as an employee in the questionnaire response. Also, one of the medium-sized manufacturing workplaces in the research relied on team of casual labour to respond to any increase in demand. In a workplace of 50 total employees, a further 8 casual staff were excluded from the discussion of workplace skills, career paths, or remuneration strategies.

Contractors: Another important definitional issue was the distinction between casuals and contractors. Here the issue is defining who the employer is. We begun with the distinction being about who decides how the work is done but this did not work well. We found examples where contractors were doing the same work as 'permanent' staff but were only called in during irregular peak times. One possible distinction could be drawn between employees and contractors on the basis of ownership of equipment. For example, one workplace contracted out delivery services to drivers in the event that their own trucks could not cover demand. The contractors were owner drivers rather than drivers of the workplace's trucks. But if the issue is how much direction is given over how the work is done then any empirical distinction will be confounded by managers' varying perceptions.

This is perhaps a good argument for including contractors in a survey as suppliers of labour to workplaces, particularly if 'non-standard' work is an area of interest. Perhaps we need 
to be focusing on the supply of labour to workplaces rather than employees. We should be interested in who does what in the workplace rather than legal contractual arrangements which means including contractors as suppliers of labour.

There is a continuum of employment arrangements ranging from employees with job security through those employed on a temporary or fluctuating basis to those who are contractors and although not technically considered employees nonetheless perform tasks similar to those of employees. Arbitrarily drawing a line between different groups has been previously done in reference to a "standard" often defined with reference to awards but this is no longer appropriate.

Employment Contracts: Another definitional problems arose around the issue of employment contracts. There was a great deal of confusion as to whether existing employment contracts were individual or collective, or whether sets of wages and conditions are individual or collective. One manager for example referred to how they had an "individual employment contract situation" in the interview but reported in the questionnaire response that $40 \%$ of employees were on two collective contracts. But perhaps some of this was due to our own lack of clarity as to whether we were interested in finding out if wages and conditions are set to cover a groups/ individuals or whether we were interested in finding out whether contracts are written to cover groups/individuals. This is an important questions for researchers to keep in mind. This issue is alluded to by Harbridge and Honeybone (1995) who in their collective contracts data base, treat the "small number" of individual level contracts as collective contracts because "they are the same for all staff".

\section{Sampling Issues}

Identifying business characteristics: While the research design (stratifying for relevant variables) demanded a quota sampling approach, this was made more difficult by the fact that there is often limited or no information available on these variables before contact with the workplace. This was countered here by oversampling, but this seems an unnecessary and wasteful step. A related problem is that finding small businesses is much harder than we initially expected. Publications listing such businesses go out of date very quickly, particularly for small business with higher turnover rates, and neither the Business Who's Who or the Yellow Pages are entirely comprehensive. This has serious implications should a larger random sample be drawn using either (or a combination of) these sources.

We had more joy with larger companies, but found that addressing our initial letter to 'The General Manager' was a serious mistake. Many companies had no-one with that job description and the letter got lost in the corporate labyrinth. Much better to find the name of the person you believe to be the appropriate 'gatekeeper' at each research site, perhaps by calling the company before mailing the letters. We are convinced that, to have any chance of success, approaches to companies of any size need to be customised and personalised rather than generic.
Unit of analysis: A related sampling problem emerges because the workplace is not always the unit where employment and wage decisions are made and in some cases decisions are made at more than one management level within an organisation. For example, employment contracts may be set at a divisional level but recommendations for skill and seniority increments made by branch managers. Similarly, franchises provide a common way that people can enter their own small business (Hamilton and English, 1993:150) but these limit the amount of workplace autonomy available to the franchisee. Future surveys need to consider including both the workplace manager and the company employee relations manager.

Response rate and bias: Finding small businesses still in business who would agree to take part in the research was difficult. But even where we found businesses still operating, large numbers of the smallest ones refused to participate in the research. We commonly experienced businesses which thought the research was a good idea but which reported having neither the time or energy to participate. Calls to many such companies were met with responses such as 'I'm far too busy' or 'time is money'. Implicit in many of these refusals was that those small businesses could see no direct benefit to themselves from participation. A research design that can point to tangible benefits for the small business holder, as well as involve them outside of working hours, would seem to be a much more practicable approach.

In addition the choice of the survey method itself proved to be problematic. Many managers reported receiving questionnaires every month from various places such as industry organisations, employer organisations, and universities, including a 'Brisbane University'. Because of the number of questionnaires received they were seen as a nuisance and weren't often completed. This kind of 'questionnaire overload' and 'questionnaire fatigue' has been commented on before by market researchers (Young, 1996:32), and here we have further experience of researchers 'tripping over themselves'.

Of interest, however, is the fact that some of the managers who refused to fill out the mail questionnaire still agreed to be interviewed. The notion that the interview is a preferred method of research participation rather than filling out questionnaires is supported by the fact that out of the 19 interviews carried out only eight managers returned their completed questionnaire.

\section{Matching employer and employee information}

Access to employees: In the design phase of this research, the generation of 'matched sets' of data were seen as one of the real strengths of the chosen approach. However, realising the benefits of such a design were much more difficult that we anticipated. This was partially caused by a real reluctance on the part of some employers to pass questionnaires on to employees even though they were willing to be interviewed and willing to complete a questionnaire themselves. We were surprised to find that most employers interviewed made some reference to how employees would find it too 
difficult to fill out a questionnaire. An example of this attitude can be seen in this response from a manager of a manufacturing operation with 35 staff

... any paperwork is seen as an evil to be avoided, it is a major challenge to have even basic paperwork systems introduced ... Most of our staff have relatively low written communication skills and for many English is a second language ...

In a number of cases management refused to pass the employee questionnaires onto employees because they judged the questionnaire too hard or beyond the comprehension of those employees. This remained the case despite the fact that the employee questionnaires we had returned were consistently completed correctly.

Some also considered that employee questionnaires may cause 'unrest'. Part of the questionnaire asked about what benefits employees received by listing common kinds of benefits. Some employers believed that this may raise the consciousness of employees and create dissatisfaction where there was currently (seeming) satisfaction about wages and conditions. Possible strategies to overcome this problem include, gaining greater commitment to participating from managers, asking more open ended questions of the employees, and researchers actively collecting data rather than sending questionnaires.

A further access issue is that our research design means that the research team has no control over which employees the questionnaires are distributed to. This means the data may be systematically biased. This may require involving all employees at a workplace rather than a selection.

Contradictory responses: The validity of 'matched data sets' is called into question by the fact there are repeated examples of manager and employee responses conflicting. For example, in two workplaces the manager said no employees were union members yet two of the six employees who responded reported being union members. This raises important questions about the validity and reliability of any workplace research that draws conclusions entirely from the responses of management (and, equally, entirely from employees).

\section{Comparing small and large workplaces}

A difficulty that arises in comparing small and large workplaces relates to whether the research aims to describe what formal structures are in place as opposed to what actually occurs in the workplace. Career paths is a good example where large workplaces may have formal promotion channels which do not exist in small workplaces. This was noted in Savage (1989). However in small workplaces there may be promotional opportunities that arise when required for a suitable employee. One example is from a small manufacturing and distribution warehouse (18 full time staff) where a machine operator transferred to clerical duties, driving and eventually to a sales rep position which is the highest paid. This career path arose after the employee suffered an injury which necessitated the move from production to clerical work. Other employees have since expressed interest in doing the same so even though there is no formal structure of sequential jobs and promotion rules, in effect a career path is operating in that workplace. Another example is from a small service operation with 3 staff where one staff member was seen as particularly able and there were plans to set them up with their own team separate from the team led by the employer. In two larger workplaces (with 50-100 staff) the only career paths mentioned were for management trainees who would learn different jobs before proceeding to management. No career paths were in place for production workers.

The essential difference between career paths in small and large workplaces is that in large, careers may be structure employees slotted into them whereas in small careers may be set up around suitable employees. But the main point is that the notion that small workplaces tend to offer more dead end jobs may be false and asking questions about formalised structures will give a biased picture.

\section{Conclusion}

This paper emerged from the first stage of a multi-disciplinary research project. Our work has provided some important lessons about researching workplaces. Three main points have emerged. Firstly, more time needs to be spent getting employers committed to participating fully in the research, by involving them more in the process and providing them with tangible outcomes. Secondly, in relation to definitional problems encountered, we suggest a re-conceptualisation of the empoyment relationship in terms of who supplies 'labour' to the workplace, rather than only including those who are technically employees. Thirdly, our work has highlighted the difference between what actually happens in the workplace and formal written policies and structures. Our future work will concentrate on the former.

\section{Future research}

The intention of the research team is to undertake a pilot survey next year. This will take into account the theoretical and methodological issues raised in this paper. A key issue is to re-conceptualise the distinction between 'standard' and 'non-standard' work. Another issue relates to asking questions about what actually happens in the workplace rather than what formalised structures are in place.

The team will be continuing to develop a multi-disciplinary theoretical framework. The aim of multi-disciplinary research is to explore work from different perspectives. The fact that this research was designed by a team people of varied academic backgrounds (economics, political science, psychology, and sociology) means that what really drove the research was compromise. As a result, the researchers maintain a little piece of an overly long questionnaire which reflects their own interests but which provides a disintegrated whole. There was never the opportunity to move the research from its multi-disciplinary roots towards the synergetic 'inter-disciplinary' mode that we had anticipated. 


\section{References}

Bradford, S 1993 Women and Unemployment, in Women's Electoral Lobby, Walking Backwards into the Future Women's Electoral Lobby, Hamilton.

Haines, L 1989 Work Today: Employment Trends to 1989, New Zealand Planning Council, Wellington.

Hamilton, R. and English, J. 1993 The Small Business Book: A New Zealand Guide, Bridget Williams Books, Wellington

Harbridge, Raymond 1993 'Collective employment contracts: a content analysis'. In Harbridge, Raymond (ed.) Employment Contracts: New Zealand Experiences Victoria University Press, pp70-88.

Harbridge, Raymond and Honeybone, A. 1995 The Employment Contracts Act and Collective Bargaining Patterns: A Review of the 1994/95 Year. In Harbridge, Raymond and Kiely, Peter, (eds) Employment Contracts: Bargaining Trends and Employment Law Update 1994/95. Wellington, Industrial Relations Centre, Victoria University of Wellington,

Leibrich, J. 1993 Straight to the point, University of Otago Press, Dunedin

National Board of Employment, Education and Training 1992 Disadvantaged jobseekers: casual, parttime and temporary Work, Commissioned Report No.18, Australian Government Publishing Service

Ryan, Rose 1996 'Should New Zealand have a WIRS?" The Labour Market Bulletin, 1:101-111.

Sarantakos, S. 1993 Social Research, McMillan Education Australia, Melbourne,

Savage, J. 1989 Internal Labour Markets, NZIER Research Monograph 45, Wellington

Young, C 1996 New perspectives, new paradigms, Marketing, February: 32-35.

\section{Authors}

Cushla Paice is a lecturer in Department of Economics, Massey University - Albany Campus, Private Bag 102904, Auckland.E-mail: C.M.Paice@massey.ac.nz

Carl Davidson is a lecturer in Sociology Department, Massey University - Albany Campus, Private Bag 102904, Auckland.E-mail: C.P.Davidson@massey.ac.nz
Hilary Bennett is a lecturer in Psychology Department, Massey University - Albany Campus, Private Bag 102904, Auckland. E-mail: H.F.Bennett@massey.ac.nz

Mike O'Brien is a senior lecturer in Social Policy and Social Work, Massey University - Albany Campus, Private Bag 102904, Auckland. E-mail: M.A.Obrien@massey.ac.nz 